\title{
Phase Transformations in Steels: Processing, Microstructure, and Performance
}

\author{
PAUL J. GIBBS ${ }^{1,2}$ \\ 1.-Materials Science and Technology Division, Los Alamos National Laboratory, PO Box 1663, \\ MS G770, Los Alamos, NM 87545, USA. 2.-e-mail: pgibbs@lanl.gov
}

Contemporary steel research is revealing new processing avenues to tailor microstructure and properties that, until recently, were only imaginable. Much of the technological versatility facilitating this development is provided by the understanding and utilization of the complex phase transformation sequences available in ferrous alloys. Today we have the opportunity to explore the diverse phenomena displayed by steels with specialized analytical and experimental tools. Advances in multiscale characterization techniques provide a fresh perspective into microstructural relationships at the macro- and micro-scale, enabling a fundamental understanding of the role of phase transformations during processing and subsequent deformation.

In the phase transformations in steels focus section of the May JOM issue, a series of articles is presented highlighting several diverse aspects of ferrous phase transformations in the design, application, and performance of modern steels. In the article "Multiscale Modeling of Phase Transformations in Steels," M. Militzer, J.J. Hoyt, N. Provatas, J. Rottler, C.W. Sinclair, and H.S. Zurob discuss the application of multiscale modeling techniques to enable rapid development of processing strategies, while F.G. Caballero, C. GarciaMateo, and M.K. Miller present how phase transformation fundamentals are being used to refine bainitic steel microstructures from ultra-fine to nanometer-length scales in their article titled "Design of Novel Bainitic Steels: Moving From Ultra Fine To Nanoscale Structures." G.R. Lehnhoff and K.O. Findley in their article titled "The Martensitic Transformation and Strain Hardening
Behavior of Austenitic Steels During Fatigue and Tensile Loading" present the interplay between stacking fault energy and metastable austenite transformation on room-temperature, low-cycle fatigue performance, emphasizing the sensitivity of various mechanical properties to metastable austenite transformation. Presenting the importance of phase transformations during processing in the article titled "Dynamic Ferrite Transformation Behaviors in 6Ni-0.1C Steel," Nokeun Park, Lijia Zhao, Akinobu Shibata, and Nobuhiro Tsuji discuss the implications of dynamic ferrite transformation from austenite during hot-rolling for grain refinement in a high nickel steel while A.J. Levinson, D.J. Rowenhorst, and A.C. Lewis ("Quantification of Microstructural Evolution in Grain Boundary Networks") and G. Pimentel, J. Chao, and C. Capdevila ("Recrystallization Process in $\mathrm{Fe}-\mathrm{Cr}-\mathrm{Al}$ Oxide Dispersion Strengthened Alloy: Microstructural Evolution and Recrystallization Mechanism") present two very different aspects of the role of recrystallization on the final microstructure. Importantly, several of the contributed articles represent the work of students, emphasizing the significant contributions of young professionals to the ferrous community. Although the diversity of these articles is impressive, they still only represent a small portion of the state-of-the-art research currently focused on understanding phase transformations in steels. Phase transformations in steels captured the interest of the first metallurgists as far back as the 1880s and remain today as one of the great opportunities for research to advance structural materials to meet evolving performance demands. 